Research Article

\title{
Glass Forming Ability, Thermal Stability, and Magnetic Properties of FeCoNiBSi Alloys with Different B Contents
}

\author{
Haibo Sun (iD $^{1}$ and Yongfei Wang $\mathbb{D}^{2}$ \\ ${ }^{1}$ School of Materials Science and Energy Engineering, Foshan University, Foshan, Guangdong 528000, China \\ ${ }^{2}$ China Amorphous Technology Co., Ltd., Foshan, Guangdong 528241, China \\ Correspondence should be addressed to Haibo Sun; sunmyseven@126.com
}

Received 24 February 2018; Accepted 24 April 2018; Published 13 May 2018

Academic Editor: Gianluca Gubbiotti

Copyright ( 2018 Haibo Sun and Yongfei Wang. This is an open access article distributed under the Creative Commons Attribution License, which permits unrestricted use, distribution, and reproduction in any medium, provided the original work is properly cited.

The dependence on the glass forming ability, magnetic property, and thermal stability of the $\left(\mathrm{Fe}_{0.39} \mathrm{Co}_{0.15} \mathrm{Ni}_{0.46}\right)_{82-x} \mathrm{~B}_{12+x} \mathrm{Si}_{6}(x=0,2$, 4 , and 6) alloys was investigated. The results show that the as-quenched alloy ribbons exhibit a completely amorphous structure with B content in the range of $12 \sim 18$ at.\%. The initial crystallization onset temperature of the as-quenched ribbon increases with the increase of B content. When the B content is up to 14 at.\%, the temperature interval between the two crystallization peaks will sharply reduce, which narrows the effective annealing range that is detrimental to improving the soft magnetic properties. Both of the Ms and $\mathrm{Hc}$ of the as-quenched ribbons increase first and then decrease with the increase of B content. Here, the maximum Ms of $0.90 \mathrm{~T}$ and low $\mathrm{Hc}$ of $10.2 \mathrm{~A} / \mathrm{m}$ can be obtained at the $\mathrm{B}$ content of 14 at.\%. Additionally, the $\left(\mathrm{Fe}_{0.39} \mathrm{Co}_{0.15} \mathrm{Ni}_{0.46}\right)_{80} \mathrm{~B}_{14} \mathrm{Si}_{6}$ alloy exhibits the minimum $\mathrm{Hc}$ of $5.9 \mathrm{~A} / \mathrm{m}$ and $\mathrm{Ms}$ of $0.934 \mathrm{~T}$ at the proposed annealing temperature of $698 \mathrm{~K}$ for $10 \mathrm{~min}$ in the vacuum condition.

\section{Introduction}

Soft magnetic amorphous alloys have been well known in the various electromagnetic applications, such as sensors, transformers, and electronic and power devices [1-3] because of their excellent magnetic properties including the high saturation magnetization, ultrahigh magnetic permeability, and low coercive force [3-5]. $\mathrm{Fe}_{40} \mathrm{Ni}_{38} \mathrm{Mo}_{4} \mathrm{~B}_{18}$ (Metglas2826MB) amorphous alloy was the earliest magnetic material $[6,7]$ applied to the acoustomagnetic antitheft label and received a lot of attentions and debates. Srivastava et al. [8] investigated the microstructure and magnetic properties of $\mathrm{Fe}_{40} \mathrm{Ni}_{38} \mathrm{Mo}_{4} \mathrm{~B}_{18}$ at the various degrees of crystallization from the amorphous state and found that the $(\mathrm{Fe}, \mathrm{Ni}, \mathrm{Mo})_{23} \mathrm{~B}_{6}$ phase and $\mathrm{FCC}(\mathrm{Fe}, \mathrm{Ni})$ solid solution can be formed after the crystallization at the annealing temperatures around $414^{\circ} \mathrm{C}$ and $522^{\circ} \mathrm{C}$. Szewczyk et al. [9] studied the initial curve and major and minor magnetostriction hysteresis butterfly loops of the as-quenched $\mathrm{Fe}_{40} \mathrm{Ni}_{38} \mathrm{Mo}_{4} \mathrm{~B}_{18}$ amorphous alloy as a function of quasistatic magnetic field. Liang et al. [10] pointed out that the additive of $B$ can remarkably reduce the remanence of the amorphous FeNi$\mathrm{MoB}$ thin films. However, application of the amorphous
$\mathrm{Fe}_{40} \mathrm{Ni}_{38} \mathrm{Mo}_{4} \mathrm{~B}_{18}$ alloy labels may cause false alarms in the electronic article surveillance (EAS) system [11] owing to that the internal stress distribution of the FeNiMoB alloy is associated with a nonlinear hysteresis loop [12]. Thus, the amorphous FeCoNiBSi alloy [13] proposed by Hezer is popularly used for the magnetic EAS labels at present because of its properties of moderate magnetostriction $(<5 \mathrm{ppm})$ and corrosion resistance [14].

Considering the further development of this FeCoNiBSi alloy as an engineering material, it is extremely important to find the balance between the low cost and high magnetic property. The metalloid element of boron (B) is beneficial to the glass formation ability improvement, amorphous structure stabilization, and grain refinement for the Fe-based amorphous alloys [15]. It is well known that Fe-B amorphous alloys can be formed in the composition with $\mathrm{B}$ content in the range of $12-28 \%$ at.\% [16] by melt-spinning process. Wang et al. [17] indicated that amorphous phases can be formed in a wide B-content range of 11 31 at.\% for ( $\mathrm{Fe}, \mathrm{Co}, \mathrm{Ni}, \mathrm{Cr}, \mathrm{Mo}$ )-B amorphous alloys. Moreover, Yao et al. [18] investigated the effect of B content on crystallization, forming ability, and magnetic properties of $\mathrm{FeZrBNb}$ amorphous alloy and showed that only one exothermic peak 


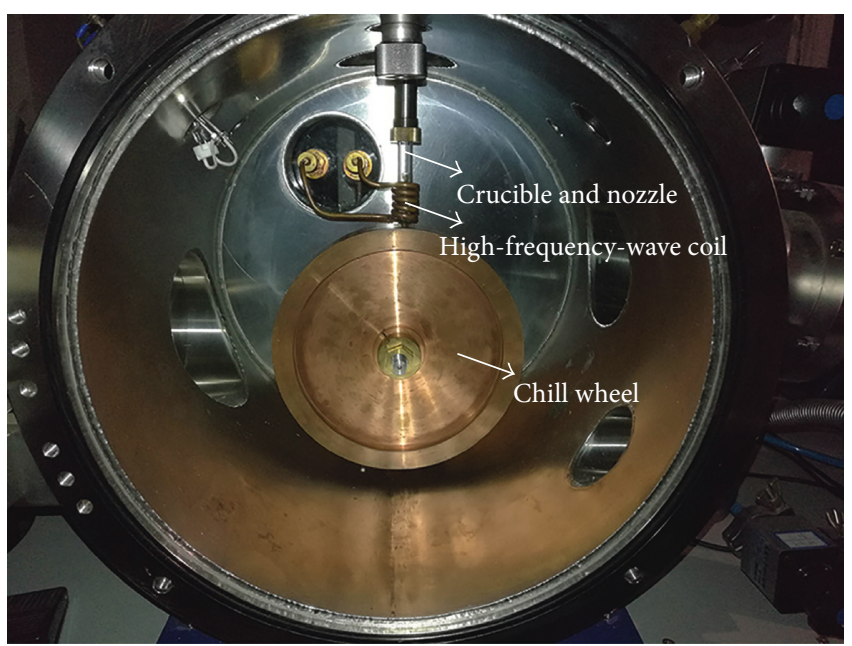

(a)

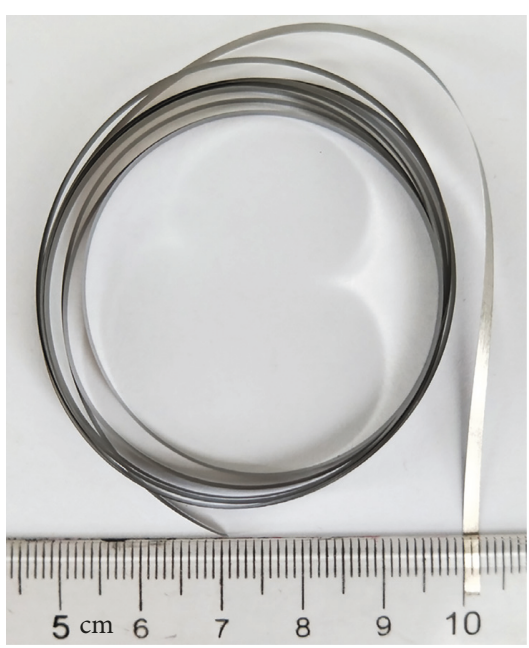

(b)

Figure 1: Schematic diagrams of single roller melt-spinning apparatus (a) and ribbon (b).

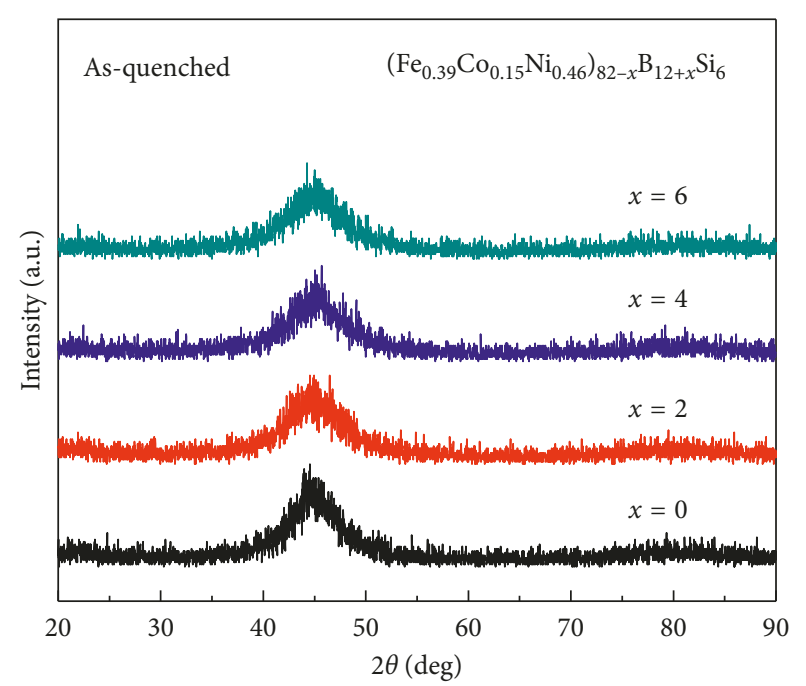

Figure 2: XRD patterns of $\left(\mathrm{Fe}_{0.39} \mathrm{Co}_{0.15} \mathrm{Ni}_{0.46}\right)_{82-x} \mathrm{~B}_{12+x} \mathrm{Si}_{6}$ asquenched ribbons.

can be observed in the DSC curves when B content exceeds 20 at.\%. Based on the discussions, the effect of B content on the glass formation ability and magnetic properties of $\left(\mathrm{Fe}_{0.39} \mathrm{Co}_{0.15} \mathrm{Ni}_{0.46}\right)_{82-x} \mathrm{~B}_{12+x} \mathrm{Si}_{6} \quad(x=0,2,4$, and 6) was studied in this work with industrial raw materials.

\section{Materials and Methods}

Alloy ingots with nominal compositions of $\left(\mathrm{Fe}_{0.39} \mathrm{Co}_{0.15} \mathrm{Ni}_{0.46}\right)_{82-x} \mathrm{~B}_{12+x} \mathrm{Si}_{6} \quad(x=0,2,4$, and 6) were prepared by melting the mixtures of industrial raw materials Fe (99.9 wt.\%), Co (99.9 wt.\%), Ni (99.9 wt.\%), Si (99.9 wt.\%), and commercial prealloyed Fe-B ingot (17.4 wt.\% B) in a high purified argon (Ar) atmosphere. The ingots were reversely remelted at least three times to enhance homogeneity. Melt-spun ribbons within width and thickness of about $0.002 \mathrm{~m}(2 \mathrm{~mm})$ and $0.00003 \mathrm{~m}(30 \mu \mathrm{m})$, respectively, were prepared by a single roller melt-spinning technique at a wheel rotating speed of $50 \mathrm{~m} / \mathrm{s}$ in the Ar atmosphere as shown in Figure 1 . The as-quenched ribbons were annealed at various temperatures with a heat rating of $20 \mathrm{~K} / \mathrm{min}$ to the specified temperature by using a tubular furnace in the vacuum atmosphere and heated for $10 \mathrm{~min}$ and then cooled to room temperature in the furnace. The phase structures of the asquenched and annealed ribbons were identified by X-ray diffraction (XRD) with $\mathrm{Cu} \mathrm{K} \alpha$ radiation. Thermal properties including crystallization onset temperature $\left(T_{\mathrm{x}}\right)$ and peak temperature $\left(T_{\mathrm{p}}\right)$ were evaluated by using differential scanning calorimeter (DSC) at a heating rate of $20 \mathrm{~K} / \mathrm{min}$. Saturation magnetization intensity (Ms) and coercive force $(\mathrm{Hc})$ were measured with a vibrating sample magnetometer (VSM) under the maximum applied field of $1,200,000 \mathrm{~A} / \mathrm{m}$ and a DC $\mathrm{B}-\mathrm{H}$ loop tracer under a field of $800 \mathrm{~A} / \mathrm{m}$, respectively. The density of the ribbons is about $7.40 \mathrm{~g} / \mathrm{cm}^{3}$, which was obtained by the Archimedes method.

\section{Results and Discussions}

3.1. Materials Design. Figure 2 shows the representative XRD patterns of the as-quenched $\left(\mathrm{Fe}_{0.39} \mathrm{Co}_{0.15} \mathrm{Ni}_{0.46}\right)_{82-x} \mathrm{~B}_{12+x} \mathrm{Si}_{6}$ $(x=0,2,4$, and 6$)$ alloy ribbons. The broad peaks at around $2 \theta=45^{\circ}$ without any other distinct diffraction peaks exhibiting amorphous structures can be detected for all asquenched ribbons with B content in the range of $12-18$ at.\%. Figure 3 displays the DSC curves of the corresponding asquenched ribbons with different B contents. It is observed that the crystallization processes of these ribbons proceed in two stages: the initial crystallization onset temperature $\left(T_{\mathrm{x} 1}\right)$ indicates the precipitation of $\gamma$-FeNi phase, and the second one $\left(T_{\mathrm{x} 2}\right)$ corresponds to complete crystallization of the remaining amorphous phase. Detailed results of DSC curves are summarized in Table 1 . It is seen that the $T_{\mathrm{x} 1}$ of the asquenched ribbon increases from $707.45 \mathrm{~K}$ to $778.35 \mathrm{~K}$ with the increase of B content from 12 at.\% to 18 at.\%, which indicates that the increase of $\mathrm{B}$ content is beneficial to the 


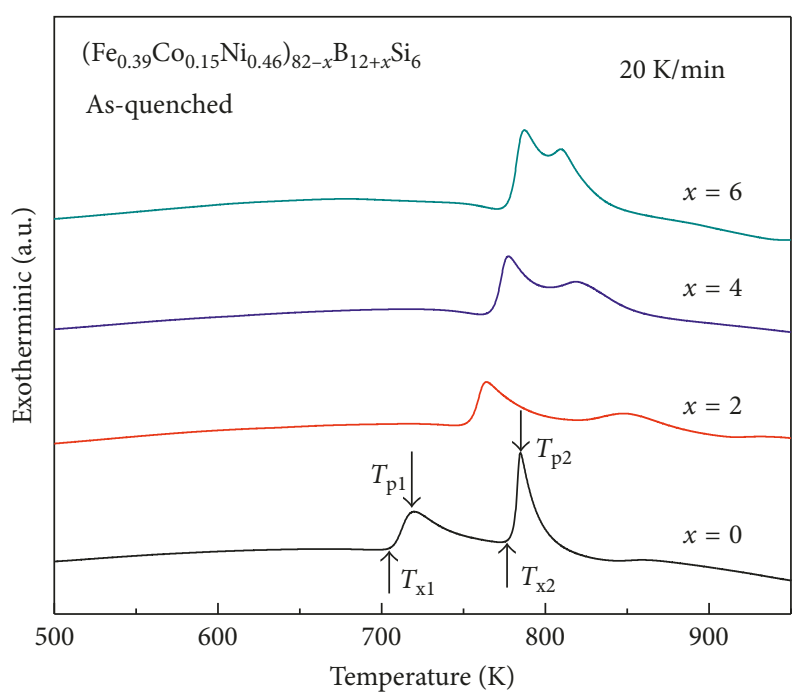

FIGURE 3: DSC curves of $\left(\mathrm{Fe}_{0.39} \mathrm{Co}_{0.15} \mathrm{Ni}_{0.46}\right)_{82-x} \mathrm{~B}_{16+x} \mathrm{Si}_{6}$ as-quenched ribbons.

TABLE 1: Thermodynamic parameters of $\left(\mathrm{Fe}_{0.39} \mathrm{Co}_{0.15} \mathrm{Ni}_{0.46}\right)_{82-x} \mathrm{~B}_{12+x} \mathrm{Si}_{6}$ as-quenched ribbons.

\begin{tabular}{lccccc}
\hline Compositions & $T_{\mathrm{x} 1}(\mathrm{~K})$ & $T_{\mathrm{p} 1}(\mathrm{~K})$ & $T_{\mathrm{x} 2}(\mathrm{~K})$ & $T_{\mathrm{p} 2}(\mathrm{~K})$ & $\Delta T_{\mathrm{x}}=T_{\mathrm{x} 2}-T_{\mathrm{x} 1}(\mathrm{~K})$ \\
\hline$\left(\mathrm{Fe}_{0.39} \mathrm{Co}_{0.15} \mathrm{Ni}_{0.46}\right)_{82} \mathrm{~B}_{12} \mathrm{Si}_{6}$ & 707.45 & 719.85 & 780.55 & 784.75 & 73.1 \\
$\left(\mathrm{Fe}_{0.39} \mathrm{Co}_{0.15} \mathrm{Ni}_{0.46}\right)_{80} \mathrm{~B}_{14} \mathrm{Si}_{6}$ & 754.55 & 764.05 & 823.25 & 847.95 & 68.7 \\
$\left(\mathrm{Fe}_{0.39} \mathrm{Co}_{0.15} \mathrm{Ni}_{0.46}\right)_{78} \mathrm{~B}_{16} \mathrm{Si}_{6}$ & 768.75 & 777.45 & 804.25 & 818.45 & 35.5 \\
$\left(\mathrm{Fe}_{0.39} \mathrm{Co}_{0.15} \mathrm{Ni}_{0.46}\right)_{76} \mathrm{~B}_{18} \mathrm{Si}_{6}$ & 778.35 & 787.15 & 802.35 & 809.45 & 24 \\
\hline
\end{tabular}

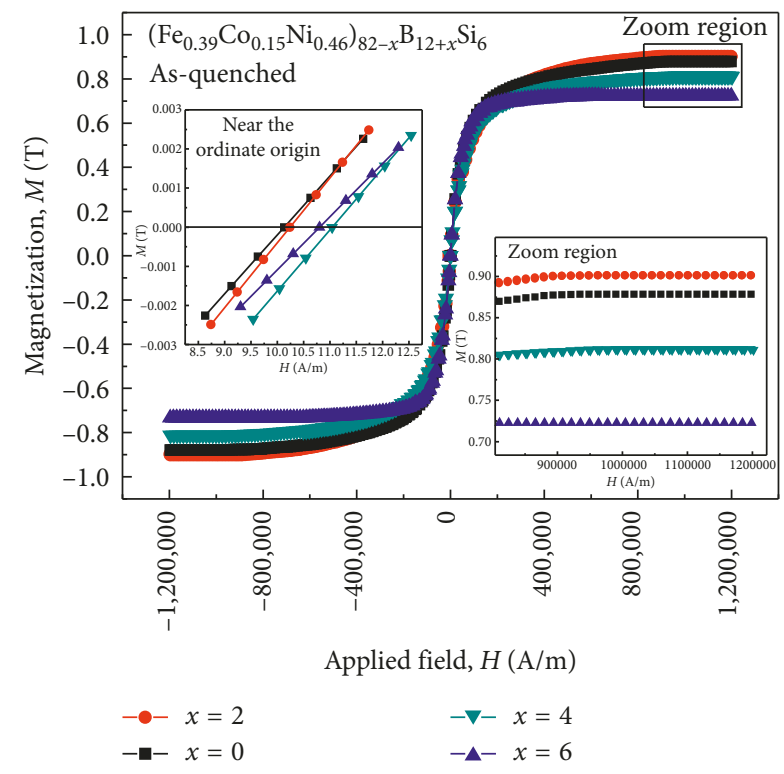

(a)

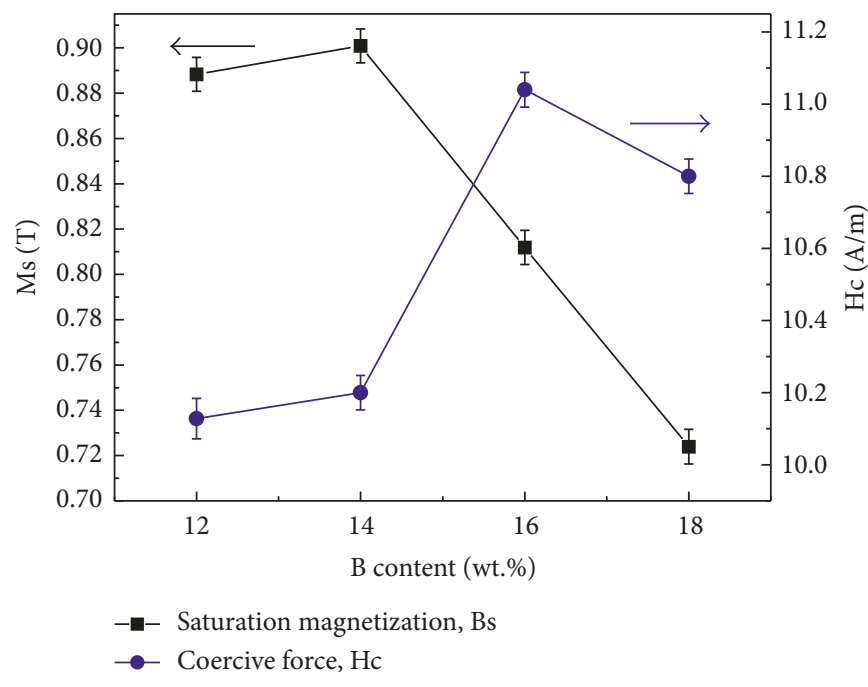

(b)

Figure 4: B-content dependence of magnetic hysteresis loop (a) and Ms and $\mathrm{Hc}$ (b) for as-quenched $\left(\mathrm{Fe}_{0.39} \mathrm{Co}_{0.15} \mathrm{Ni}_{0.46}\right)_{82-x} \mathrm{~B}_{12+x} \mathrm{Si}_{6}(x=0,2$, 4, and 6) ribbons.

thermal stability improvement for the given amorphous ribbons. However, the $T_{\mathrm{x} 2}$ of the as-quenched ribbon gradually decreases as the B content is greater than 14 at.\%. Under this situation, the temperature interval $\left(\Delta T_{\mathrm{x}}\right)$ between the $T_{\mathrm{x} 1}$ and $T_{\mathrm{x} 2}$ sharply reduces from $68.7 \mathrm{~K}$ to $24 \mathrm{~K}$ when the B content increases from 14 at.\% to 18 at.\%. That is to say, the magnitude of effective annealing temperature range will rapidly decrease as the $B$ content exceeds the critical value (14 at.\%), which is detrimental to obtaining good soft magnetic properties [19].

Figure 4 indicates the B-content dependence of the magnetic hysteresis loop, Ms, and $\mathrm{Hc}$ for the as-quenched 


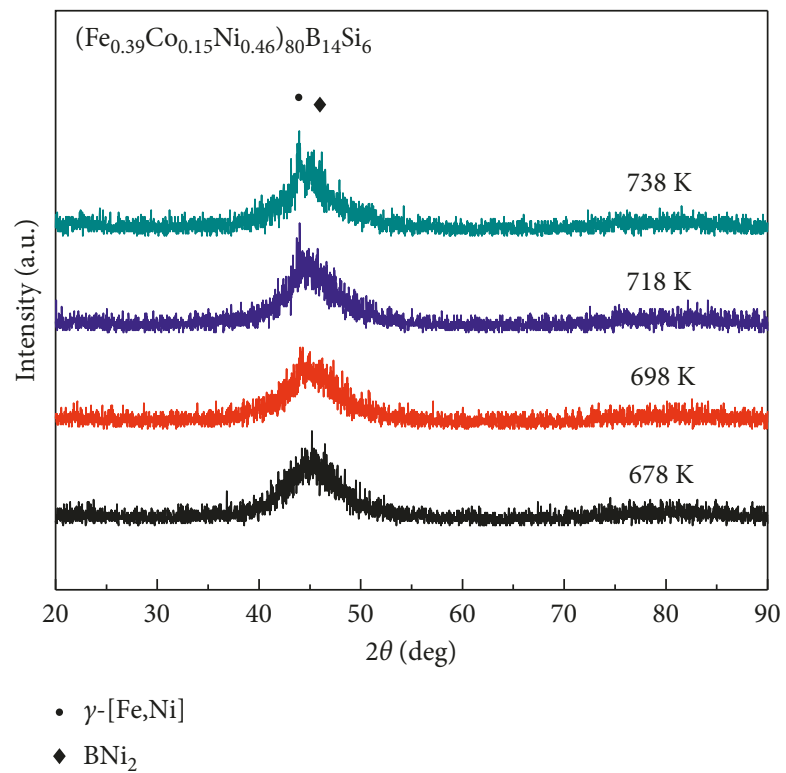

FIGURE 5: XRD patterns of as-quenched $\left(\mathrm{Fe}_{0.39} \mathrm{Co}_{0.15} \mathrm{Ni}_{0.46}\right)_{80} \mathrm{~B}_{14} \mathrm{Si}_{6}$ ribbons at various annealing temperatures.



(a)



(b)

FIGURE 6: Dependence of magnetic hysteresis loop (a) and Ms and $\mathrm{Hc}$ (b) for the as-quenched $\left(\mathrm{Fe}_{0.39} \mathrm{Co}_{0.15} \mathrm{Ni}_{0.46}\right)_{80} \mathrm{~B}_{14} \mathrm{Si}_{6} \mathrm{ribbon}_{0}$ on the annealing temperature ranging from $678 \mathrm{~K}$ to $738 \mathrm{~K}$.

$\left(\mathrm{Fe}_{0.39} \mathrm{Co}_{0.15} \mathrm{Ni}_{0.46}\right)_{82-x} \mathrm{~B}_{12+x} \mathrm{Si}_{6}(x=0,2,4$, and 6) ribbons. The value of Ms first increases gradually from $0.89 \mathrm{~T}$ to $0.90 \mathrm{~T}$ with the increase of B content from 12 at.\% to 14 at.\% and then sharply decreases to $0.72 \mathrm{~T}$ as the $\mathrm{B}$ content is up to 18 at.\% because of the reduction in the amount of ferromagnetic elements (Fe, Co, and $\mathrm{Ni}$ ) [15]. Meanwhile, the $\mathrm{Hc}$ changes in the same manner with the increase of $\mathrm{B}$ content and exhibits the minimum of $10.15 \mathrm{~A} / \mathrm{m}$ at the $\mathrm{B}$ content of 12 at.\%. It is also shown that a small increment of $0.05 \mathrm{~A} / \mathrm{m}$ for the $\mathrm{Hc}$ is observed when the $\mathrm{B}$ content increases from
12 at.\% to 14 at.\%. Therefore, the alloy within compositions of $\left(\mathrm{Fe}_{0.39} \mathrm{Co}_{0.15} \mathrm{Ni}_{0.46}\right)_{80} \mathrm{~B}_{14} \mathrm{Si}_{6}$ is proposed to be the costeffective material because of its higher $\mathrm{Ms}$ and lower $\mathrm{Hc}$ and cost than the other alloys.

3.2. Annealing Process. Figure 5 presents the XRD patterns of the as-quenched $\left(\mathrm{Fe}_{0.39} \mathrm{Co}_{0.15} \mathrm{Ni}_{0.46}\right)_{80} \mathrm{~B}_{14} \mathrm{Si}_{6}$ alloy ribbons annealed at various temperatures for $10 \mathrm{~min}$ [20] in the vacuum condition. Here, the annealing temperature range of 
$678 \sim 738 \mathrm{~K}$ was employed to control the nanostructure without precipitation of the secondary phase, which deteriorates the soft magnetic properties of ribbon, such as Fe$\mathrm{Ni}$ phase, as per the initial crystallization onset temperature $\left(T_{\mathrm{x} 1}\right)$ shown in Figure 3. The amorphous structures with the broad peaks at around $2 \theta=45^{\circ}$ can be found at the annealing temperatures of $678 \mathrm{~K}$ and $698 \mathrm{~K}$. However, as the annealing temperature is up to $718 \mathrm{~K}$, a diffraction peak at $2 \theta=44^{\circ}$ corresponding to $\gamma$-[Fe,Ni] is observed in the XRD patterns. Moreover, two obvious diffraction peaks at $2 \theta=44^{\circ}$ and $46^{\circ}$ corresponding to $\gamma$-[Fe,Ni] and $\mathrm{Ni}_{2} \mathrm{~B}$ [21], respectively, can be detected within the annealing temperature of $738 \mathrm{~K}$.

Figure 6 displays the dependence of magnetic hysteresis loop, Ms, and $\mathrm{Hc}$ for the as-quenched $\left(\mathrm{Fe}_{0.39} \mathrm{Co}_{0.15} \mathrm{Ni}_{0.46}\right)_{80} \mathrm{~B}_{14} \mathrm{Si}_{6}$ ribbon on the annealing temperature ranging from $678 \mathrm{~K}$ to $738 \mathrm{~K}$. It is observed that all the as-annealed ribbons exhibit the typical soft magnetic hysteresis loops. The Ms of the asquenched $\left(\mathrm{Fe}_{0.39} \mathrm{Co}_{0.15} \mathrm{Ni}_{0.46}\right)_{80} \mathrm{~B}_{14} \mathrm{Si}_{6}$ ribbon gradually increases from $0.90 \mathrm{~T}$ to $0.95 \mathrm{~T}$ with the increase of the annealing temperature from $678 \mathrm{~K}$ to $738 \mathrm{~K}$. After a series heat treatments, the $\mathrm{Hc}$ of the as-quenched ribbon decreases significantly from $10.2 \mathrm{~A} / \mathrm{m}$ to $5.9 \mathrm{~A} / \mathrm{m}$ in the temperature range of $678 \sim 698 \mathrm{~K}$, and the Hc exhibits the minimum value of $5.9 \mathrm{~A} / \mathrm{m}$ at $698 \mathrm{~K}$. Combined with the results of Figure 3, the decrease of the Hc can be attributed to the relief of internal residual stress and the reduction of magnetocrystalline anisotropy $[12,17]$. When the ribbons are annealed at higher temperature, the $\mathrm{Hc}$ increases rapidly because of the excessive growth of precipitations of $\gamma$-[Fe,Ni] or/and $\mathrm{Ni}_{2} \mathrm{~B}$ as per the results shown in Figure 5. Based on the above discussions, it is shown that the $\left(\mathrm{Fe}_{0.39} \mathrm{Co}_{0.15} \mathrm{Ni}_{0.46}\right)_{80} \mathrm{~B}_{14} \mathrm{Si}_{6}$ alloy exhibits the minimum $\mathrm{Hc}$ of $5.9 \mathrm{~A} / \mathrm{m}$ and $\mathrm{Ms}$ of $0.934 \mathrm{~T}$ at the annealing temperature of $698 \mathrm{~K}$. As the annealing temperature is up to $718 \mathrm{~K}$, the $\mathrm{Hc}$ and Ms of the alloy are $8.5 \mathrm{~A} / \mathrm{m}$ and $0.944 \mathrm{~T}$, respectively. In view of the sensitivity of $\mathrm{Hc}$ on annealing temperature, the reasonable annealing temperature for $\left(\mathrm{Fe}_{0.39} \mathrm{Co}_{0.15} \mathrm{Ni}_{0.46}\right)_{80} \mathrm{~B}_{14} \mathrm{Si}_{6}$ alloy is no more than $718 \mathrm{~K}$, and the proposed annealing temperature is $698 \mathrm{~K}$.

\section{Conclusions}

Dependence on the glass forming ability, magnetic property, and thermal stability of as-quenched $\left(\mathrm{Fe}_{0.39} \mathrm{Co}_{0.15} \mathrm{Ni}_{0.46}\right)_{82-x} \mathrm{~B}_{12+x} \mathrm{Si}_{6}(x=0,2,4$, and 6) alloy ribbons have been systemically investigated. The following conclusions can be drawn:

(1) The amorphous structure can be detected for all asquenched $\left(\mathrm{Fe}_{0.39} \mathrm{Co}_{0.15} \mathrm{Ni}_{0.46}\right)_{82-x} \mathrm{~B}_{12+x} \mathrm{Si}_{6}$ ribbons with the B content ranging from 12 at.\% to 18 at.\%.

(2) The $T_{x 1}$ of the as-quenched ribbon increases with the increase of $\mathrm{B}$ content, whereas the $T_{\mathrm{x} 2}$ gradually decreases as the $B$ content is greater than 14 at. $\%$. The temperature interval $\left(\Delta T_{\mathrm{x}}\right)$ between $T_{\mathrm{x} 1}$ and $T_{\mathrm{x} 2}$ reduces sharply from $68.7 \mathrm{~K}$ to $24 \mathrm{~K}$ with the increase of B content ranging from 14 at.\% to 18 at.\%, which narrows the effective annealing range that is detrimental to improving the soft magnetic properties.
(3) Both of the $\mathrm{Ms}$ and $\mathrm{Hc}$ of as-quenched $\left(\mathrm{Fe}_{0.39} \mathrm{Co}_{0.15} \mathrm{Ni}_{0.46}\right)_{82-x} \mathrm{~B}_{12+x} \mathrm{Si}_{6}(x=0,2,4$, and 6) alloy ribbons increase first and then decrease with the increase of $\mathrm{B}$ content. The $\left(\mathrm{Fe}_{0.39} \mathrm{Co}_{0.15} \mathrm{Ni}_{0.46}\right)_{80} \mathrm{~B}_{14} \mathrm{Si}_{6}$ alloy within the maximum $\mathrm{Ms}$ of $0.90 \mathrm{~T}$ and low $\mathrm{Hc}$ of $10.2 \mathrm{~A} / \mathrm{m}$ is chosen as the cost-effective material for the EAS labels as compared to the other alloys.

(4) The $\left(\mathrm{Fe}_{0.39} \mathrm{Co}_{0.15} \mathrm{Ni}_{0.46}\right)_{80} \mathrm{~B}_{14} \mathrm{Si}_{6}$ alloy exhibits the minimum $\mathrm{Hc}$ of $5.9 \mathrm{~A} / \mathrm{m}$ and $\mathrm{Ms}$ of $0.934 \mathrm{~T}$ at the proposed annealing temperature of $698 \mathrm{~K}$ for $10 \mathrm{~min}$ under the vacuum condition.

\section{Data Availability}

The data used to support the findings of this study are available from the corresponding author upon request.

\section{Conflicts of Interest}

The authors declare that there are no conflicts of interest regarding the publication of this paper.

\section{Acknowledgments}

This work was supported by the Open foundation of $\mathrm{Na}-$ tional Engineering Research Center of Near-Net-Shape Forming for Metallic Materials (Grant no. 2017005), National Natural Science Foundation of China (Grant no. 51704078), Province Natural Science Fund of Guangdong (Grant no. 2017A030313312), and Talent Research Start-Up Program of Foshan University (Grant no. gg040942).

\section{References}

[1] R. Hasegawa, "Applications of amorphous magnetic alloys in electronic devices," Journal of Non-Crystalline Solids, vol. 287, no. 1-3, pp. 405-412, 2001.

[2] C. Suryanarayana and A. Inoue, "Iron-based bulk metallic glasses," International Materials Reviews, vol. 58, no. 3, pp. 131-166, 2013.

[3] G. Herzer, "Modern soft magnets: amorphous and nanocrystalline materials," Acta Materialia, vol. 61, no. 3, pp. 718-734, 2014.

[4] X. T. Nguyen, H. K. Vu, H. M. Do, V. K. Nguyen, and V. V. Nguyen, "The effect of external magnetic field on microstructure and magnetic properties of melt-spun Nd-Fe-B/ Fe-Co nanocomposite ribbons," Advances in Materials Science and Engineering, vol. 2013, Article ID 927356, 5 pages, 2013.

[5] Y. F. Liang, S. Wang, H. Li, Y. M. Jiang, F. Ye, and J. P. Lin, "Fabrication of $\mathrm{Fe}-6.5$ wt\% $\mathrm{Si}$ ribbons by melt spinning method on large scale," Advances in Materials Science and Engineering, vol. 2015, Article ID 296197, 5 pages, 2015.

[6] R. C. O'Handley, "Magnetic materials for EAS sensors," Journal of Materials Engineering and Performance, vol. 2, no. 2, pp. 211-218, 1993.

[7] P. G. Stoyanov and G. A. Grimes, "A remote query magnetostrictive viscosity sensor," Sensors and Actuators A: Physical, vol. 80, no. 1, pp. 8-14, 2000.

[8] A. P. Srivastava, D. Srivastava, and G. K. Dey, "A study on microstructure, magnetic properties and kinetics of the nanocrystallization of $\mathrm{Fe}_{40} \mathrm{Ni}_{38} \mathrm{~B}_{18} \mathrm{Mo}_{4}$ metglass," Journal of 
Magnetism and Magnetic Materials, vol. 306, no. 1, pp. 147155, 2006.

[9] R. Szewczyk, A. Bieńkowski, and A. Kolano-Burian, "Magnetostrictive properties of $\mathrm{Fe}_{40} \mathrm{Ni}_{38} \mathrm{Mo}_{4} \mathrm{~B}_{18}$ alloy," Materials Science and Engineering: A, vol. 375-377, pp. 1137-1139, 2004.

[10] C. Liang, C. Gooneratne, D. Cha, L. Chen, Y. Gianchandani, and J. Kosel, "Development of FeNiMoB thin film materials for microfabricated magnetoelastics sensors," Journal of Applied Physics, vol. 112, no. 11, p. 113912, 2012.

[11] N. C. Liu, M. R. Lian, and J. Cantey, US Patent 5469140, 1995.

[12] G. Herzer, "Magnetic materials for electronic article surveillance," Journal of Magnetism and Magnetic Materials, vol. 254-255, pp. 598-602, 2003.

[13] G. Herzer, US Patent 6011475, 2000.

[14] F. Wang, A. Inoue, Y. Han et al., "Soft magnetic Fe-Co-based amorphous alloys with extremely high saturation magnetization exceeding 1.9 Tand low coercivity of $2 \mathrm{~A} / \mathrm{m}$," Journal of Alloys and Compounds, vol. 723, pp. 376-384, 2017.

[15] H. R. Lashgari, D. Chu, S. Xie, H. Sun, M. Ferry, and S. Li, "Composition dependence of the microstructure and soft magnetic properties of Fe-based amorphous/nanocrystalline alloys: a review study," Journal of Non-Crystalline Solids, vol. 391, pp. 61-82, 2014.

[16] R. Hasegawa and R. Ray, "Iron-boron metallic glasses," Journal of Applied Physics, vol. 49, no. 7, p. 4174, 1978.

[17] F. Wang, A. Inoue, F. L. Kong et al., "Formation, thermal stability and mechanical properties of high entropy ( $\mathrm{Fe}, \mathrm{Co}$, $\mathrm{Ni}, \mathrm{Cr}, \mathrm{Mo})-\mathrm{B}$ amorphous alloys," Journal of Alloys and Compounds, vol. 732, pp. 637-645, 2018.

[18] B. Yao, L. Si, H. Tan, Y. Zhang, and Y. Li, "Effects of high boron content on crystallization, forming ability and magnetic properties of amorphous $\mathrm{Fe}_{91-x} \mathrm{Zr}_{5} \mathrm{~B}_{x} \mathrm{Nb}_{4}$ alloy," Journal of Non-Crystalline Solids, vol. 332, no. 1-3, pp. 43-52, 2003.

[19] X. Fan, H. Men, A. B. Ma, and B. L. Shen, "Soft magnetic properties in $\mathrm{Fe}_{84-x} \mathrm{~B}_{10} \mathrm{C}_{6} \mathrm{Cu}_{x}$ nanocrystalline alloys," Journal of Magnetism and Magnetic Materials, vol. 326, pp. 22-27, 2013.

[20] P. Sharma, X. Zhang, Y. Zhang, and A. Makino, "Competition driven nanocrystallization in high Bs and low coreloss $\mathrm{Fe}-$ Si-B-P-Cu soft magnetic alloys," Scripta Materialia, vol. 95, pp. 3-6, 2015.

[21] K. Y. He, Y. H. Zhao, G. G. Li et al., "Studies of crystallization and soft magnetic properties of $\mathrm{FeNiMoB}(\mathrm{Si})$ alloys," Journal of Magnetism and Magnetic Materials, vol. 316, no. 1, pp. 34-39, 2007. 


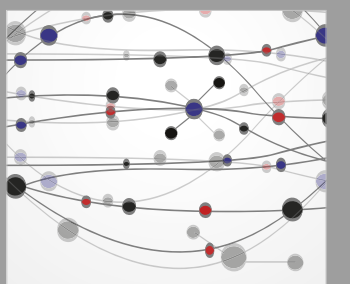

The Scientific World Journal
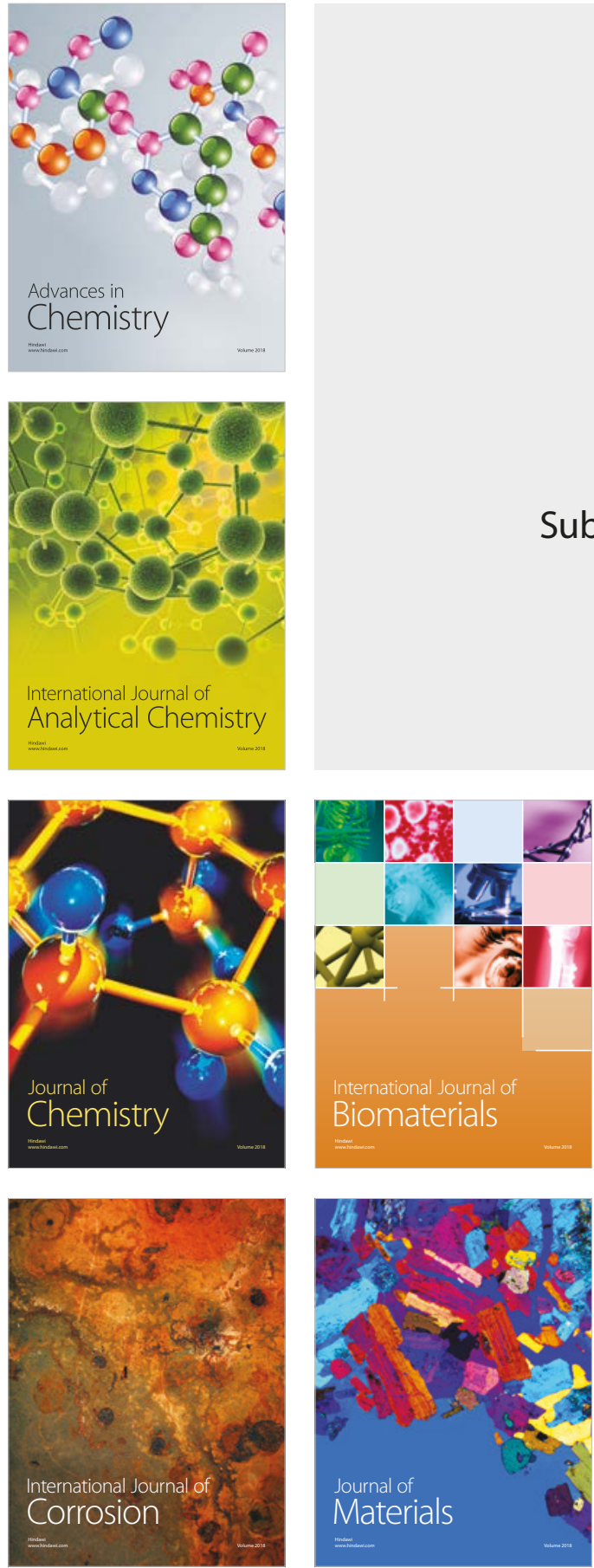

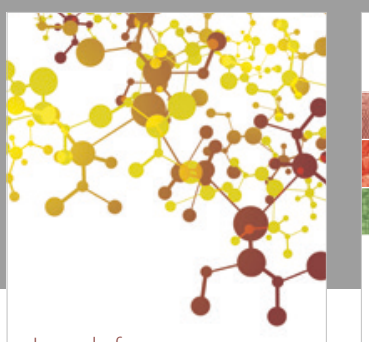

Journal of

Applied Chemistry


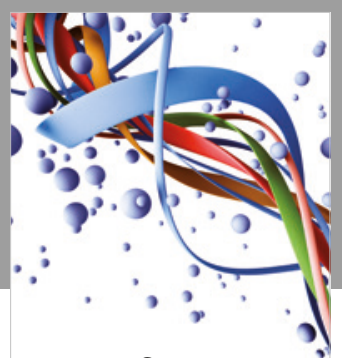

Scientifica

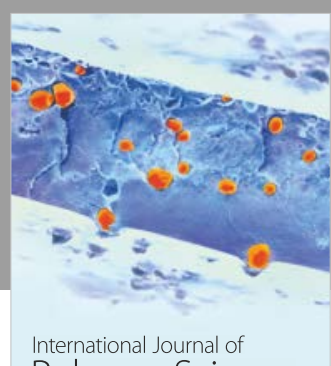

Polymer Science

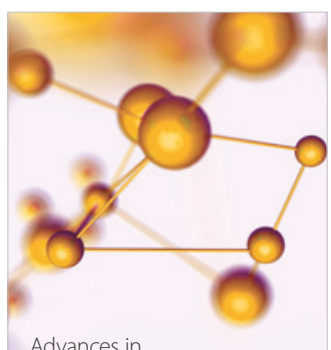

Physical Chemistry
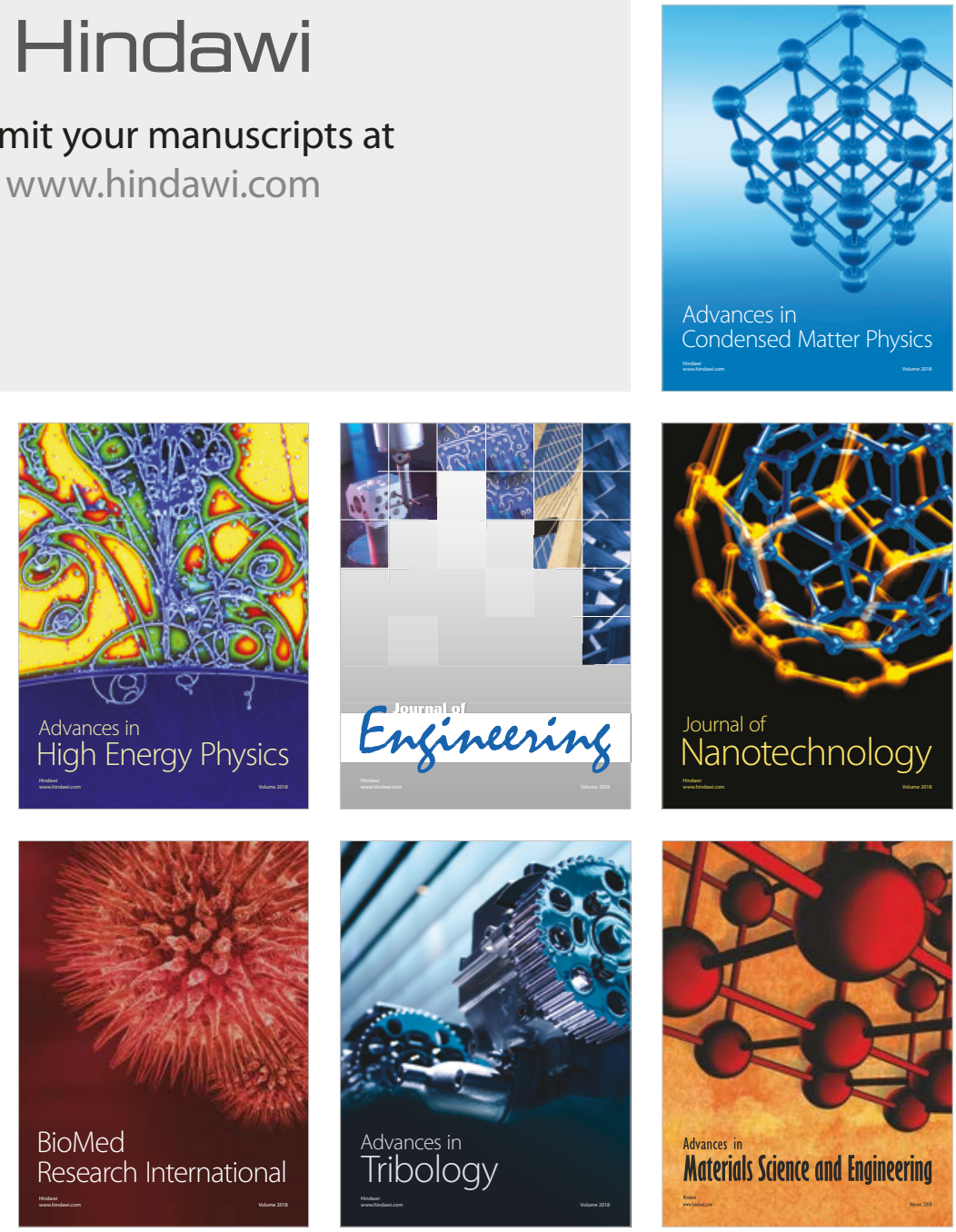